\title{
Influence of measurement conditions and used devices on consequential creep modulus
}

\author{
Martin Reznicek ${ }^{1}$, a , Martin Bednarik ${ }^{1}$, Lenka Hylova ${ }^{1}$ and David Manas ${ }^{1}$ \\ ${ }^{1}$ Tomas Bata University in Zlin, Nam. T.G. Masaryka 5555, Zlín, 76001 Czech Republic
}

\begin{abstract}
This research deals with study of the possibilities of the creep properties measurement on dedicated devices for the creep measurement and on devices, which enable the creep properties measurement. A comparison of these two different measurement methods show the influence of boundary conditions on the measurement result. Simultaneously, the effort to shorten the long-term tests, because of time saving during research and development of new materials, is confronted here. Radiation crosslinking samples of high-density polyethylene (HDPE), which enable the change of the internal structure to the spatial network by the influence of beta radiation, were chosen as an example for comparison.
\end{abstract}

\section{Introduction}

The present trend of research and development of new materials is among one of the most developing area of science and technology. The ever greater requirements of product properties make challenging demands on the material, which are produced from. Recent years progress in the area of material engineering enabled development of new devices. Testing devices, which were used in the past, are connected in the one unit with several basic methods or procedures for evaluation of material properties. Testing devices, which are used for present research and development, dispose of whole range of progressive methods, primarily with a big amount for evaluation of suitability of using material in many applications. These testing methods are mostly knowhow of the company, which is protected by the patents. Commercial devices, which are sold as a one unit, represent a significant initial investment in a comparison with devices, which is possible to make them yourself and the data to evaluate relatively cheaply from these measurement. [1-5]

Commercial programs for evaluation of data have great requirements for knowledges in the area of the structure of the work in program, more specifically, knowledge of the program in the background. This phenomenon is often called as Black Box, where the measured data is evaluated without more operator intervention. This fact may seem appropriate from the viewpoint of simplicity of evaluation, but it is undesirable from the viewpoint of effort better understanding of the material.

For this reason, some research institutes produce their own testing devices, which are more interesting from the viewpoint of the financial sector.

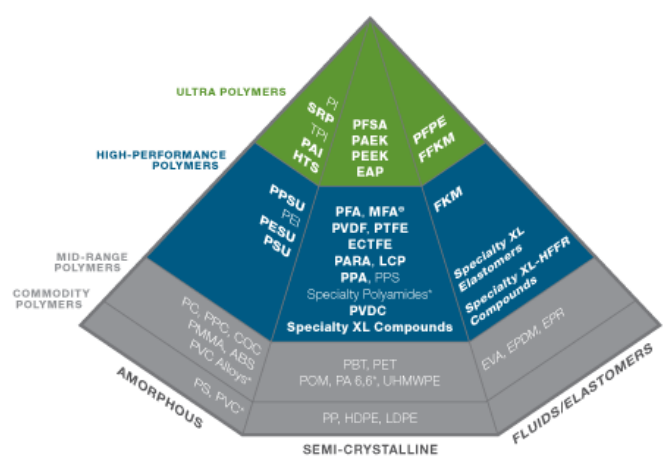

Figure 1. Separation of polymer.

It is possible to save substantial funds using correct interpretation of the results. By comparing the results of various procedures, it is possible to interpret better the conclusion obtained from own device because of detailed knowledge of the device. [6-9]

Design and realization of the proposed devices comply with specific requirements, which are required by the company or the measuring institution. By this targeted construction and mainly during evaluation of the background lead to effective use of funds, which are invested to the devices. It is very common situation that the company is very closely specialized and it is forced by customize to buy the device which is not subsequently fully utilized at $100 \%$. The measuring device has the advantage of the disposition of the possibilities which are required. The advantage of these solutions is closely profiled software which is very simple for the use and thus make lower demands on personnel qualification requirements.

\footnotetext{
${ }^{\mathrm{a}}$ Corresponding author: mreznicek@ft.utb.cz
} 


\section{Methods}

The crosslinked material was chosen for the measurement of creep properties for comparison of various options. High-density polyethylene from the company DOW was chosen as a material. Testing samples were made from this material according to a standard ISO 527-2 1BA for the tensile test. The processes of injection molding and radiation cross-linking were performed with the minimum time gap to avoid the influence on the measurement surroundings.

Process conditions were set according to the manufacturer. During subsequent quality control of specimens was detected an excessive trough in the stress part of the specimen. This undesirable effect, which could then affect the results of the measurements had to be removed. This removal is performed by changing the molding process conditions namely by increasing the holding pressure. This pressure was increased by a total of $5 \mathrm{MPa}$ which is reflected in the subsequent quality control of specimens as sufficient.

These samples were molded by the injection molding machine ARBURG Allrouder $170 \mathrm{U}$ according to the same process conditions.

Process conditions:

Table 1. Process conditions.

\begin{tabular}{|c|c|}
\hline Parameter & Value \\
\hline $\begin{array}{c}\text { Injection } \\
\text { temperature }\end{array}$ & $200^{\circ} \mathrm{C}$ \\
\hline Barrel temperatures & $195^{\circ} \mathrm{C}, 190^{\circ} \mathrm{C}, 180^{\circ} \mathrm{C}$ \\
\hline Mold temperature & $40{ }^{\circ} \mathrm{C}$ \\
\hline Injection velocity & $40 \mathrm{~mm} / \mathrm{s}$ \\
\hline Injection pressure & $60 \mathrm{MPa}$ \\
\hline Cooling time & $45 \mathrm{~s}$ \\
\hline
\end{tabular}

Apart from using a standardized sample, it was necessary to use the second part of sample too, because of the reason of restrictions loading forces on one testing device (DMA). As can be seen in Figure 2, this part had the dimensions $5 \times 3 \times 60 \mathrm{~mm}$.

This dimension during clamping proved very useful, mainly because of the need to use special screws for clamping the specimens in the fixed and movable jaws. The length of the test specimen must then be more shortened, so as to allow the use of a closing part of the test chamber.

All these samples were sent to the company B. G. S. to Germany, where the samples were irradiated by doses 33 kGy, 66 kGy, 99 kGy, 132 kGy, 165 kGy, 198 kGy. The concurrent measurement followed after irradiation on the device DMA1 from the Company Mettler Toledo and on the device for measurement of creep properties of own produce.

The most common method of loading sample is cycling loading. The construction of this device enables to test the samples at various temperatures or in various environments.

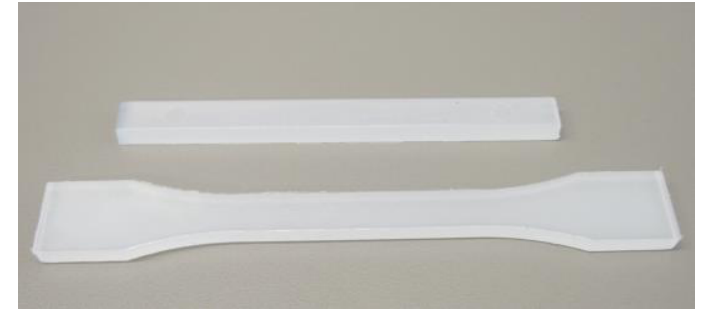

Figure 2. Samples of measurement.

Dynamic mechanical analysis (DMA) is one of the possible methods for measurement of dynamic properties. The samples for this kind of test can be exposed to tension, compression, bending and shear.

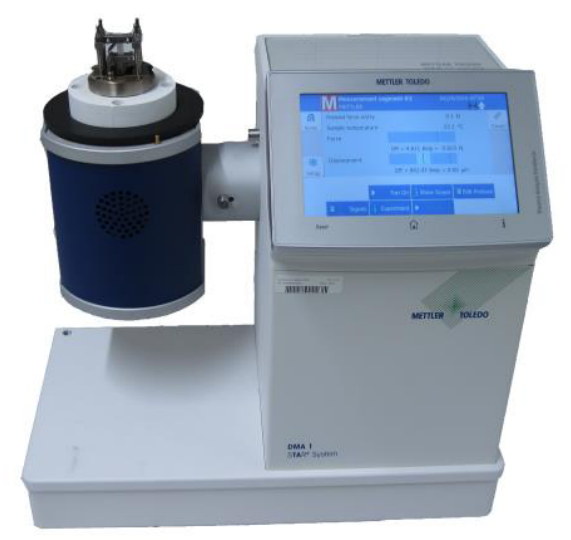

Figure 3. Mettler Toledo DMA1.

The device disposes with the mode TMA, which enables to measure the expansion, creep and relaxation time. The device DMA1 in Figure. 3 was used for measurement.

The device DMA1 enables the measurement of brittle and though materials, which are suitable for these type of loading, and it enables evaluation in the program STAR.

The load modul enables loading from 0.001 to $10 \mathrm{~N}$. The frequency generator enables the variable adjustment of oscillation from 0.001 to $300 \mathrm{~Hz}$.

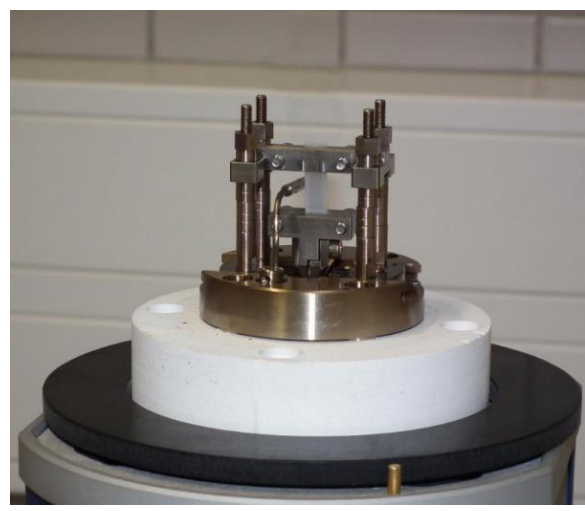

Figure 4. Clamping of sample. 
The total measuring range of deformation (displacement jaws) is $\pm 1 \mathrm{~mm}$ from the middle neutral position sensor. Whole unit can be equipped with an external device for adjusting the test temperature from 190 to $600{ }^{\circ} \mathrm{C}$. For the chosen radiation cross-linked material was selected initial voltage value $7 \mathrm{~N}$. Before the measurement, the sample was loaded only by clamping force, which was used for demarcation of clamping and determine the initial position of the sensor extension. Test duration was set for 6 hours at $22^{\circ}$ C. In Figure 5, the results can be seen.

Table 2. Parameters of Allrouder 170U.

\begin{tabular}{|c|c|}
\hline Parameter & Value \\
\hline Clamping force & $150 \mathrm{kN}$ \\
\hline $\begin{array}{c}\text { Maximal size of } \\
\text { mold }\end{array}$ & $170 \times 170 \times 200 \mathrm{~mm}$ \\
\hline Screw diameter & $22 \mathrm{~mm}$ \\
\hline $\begin{array}{c}\text { Maximal injection } \\
\text { volume }\end{array}$ & $34 \mathrm{~cm}^{3}$ \\
\hline
\end{tabular}

\section{Data of results}

Figure 5 shows the values of the minimum and the maximum progress, which have the same trend. The value of the arithmetic average is calculated from all measurements and was used for calculating of creep modulus during the test. This progress is calculated from the equation:

$$
E_{t}=\frac{F L_{0}}{A(\Delta L)_{t}}
$$

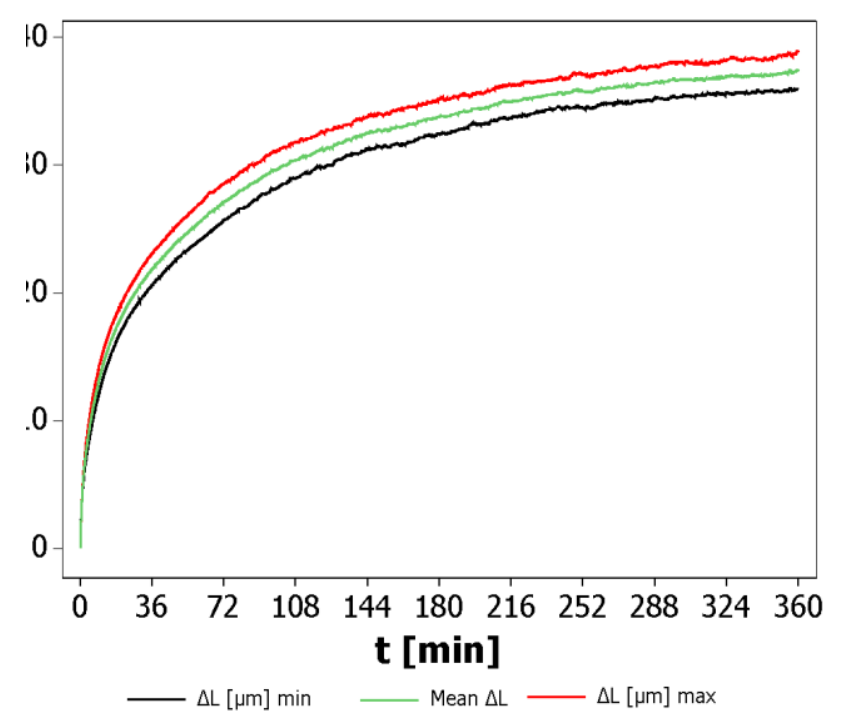

Figure 5. Results of measurement DMA for HDPE $132 \mathrm{kGy}$.

Where $E_{t}$ is creep modulus in time $t, L_{0}$ is initial value $10 \mathrm{~mm}, \mathrm{~A}$ is initial cross-section of testing sample 15 $\mathrm{mm}^{2}$.

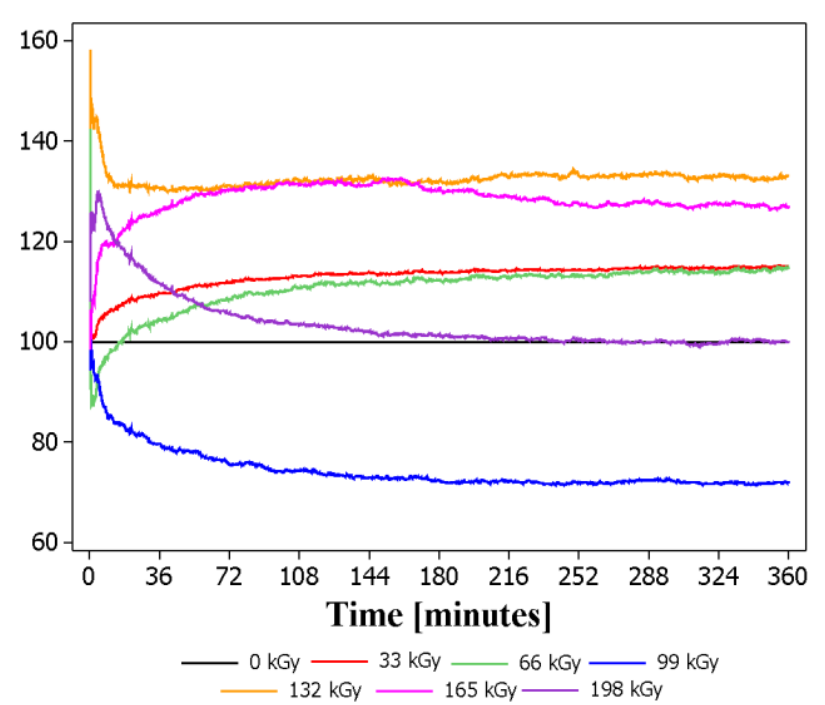

Figure 6 DMA tensile creep modulus.

\section{Measurement of creep properties in the longer term}

As a second option of the research of creep properties is its measurement on device, which is used for long-term measurement of deformation of the sample.

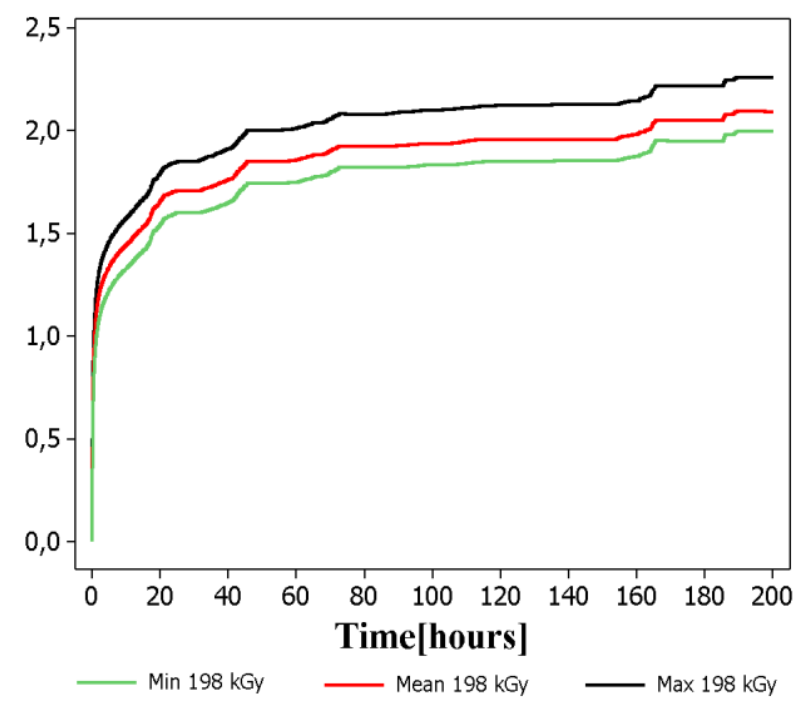

Figure 7. Illustration of results of measurement on simple device.

These devices are generally intended for one type of the test and therefore their construction is simple. The basic parameters of these measuring units are often closely linked with the intended purpose of use. The parameters of each device may vary mainly in the values of loading, reading accuracy and the complexity of the operation. The example of this type of the test is shown in Figure 7.

In Figure 8 can be seen the curve extension for HDPE irradiated by different doses. Each curve represents the mean value of the measured data in terms of the median. 
Sample size was eight measurements. As can be seen in comparison with Figure 9, these results closely correspond.

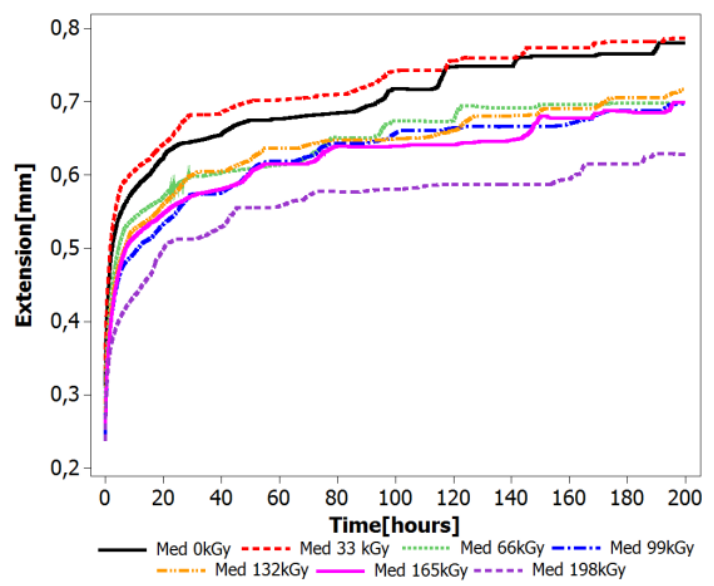

Figure 8 Extension for normal creep test.

Unirradiated material (indicated as $0 \mathrm{kGy}$ ) is compared to the dose of $66 \mathrm{kGy}$ and more throughout the measurement worse. Only at doses $33 \mathrm{kGy}$ since the beginning of the measurement worsening, which may explain the low degree of crosslinking and a high degree of decay of the original chains.

\section{Conclusion}

Figure 6 and 9 shows the results of various improvement of creep modulus in time. The results, which were measured on devide DMA1, show the differences in the primary test phase. Stabilization of creep modulus, which do not change rapidly, appears in the secondary test phase.

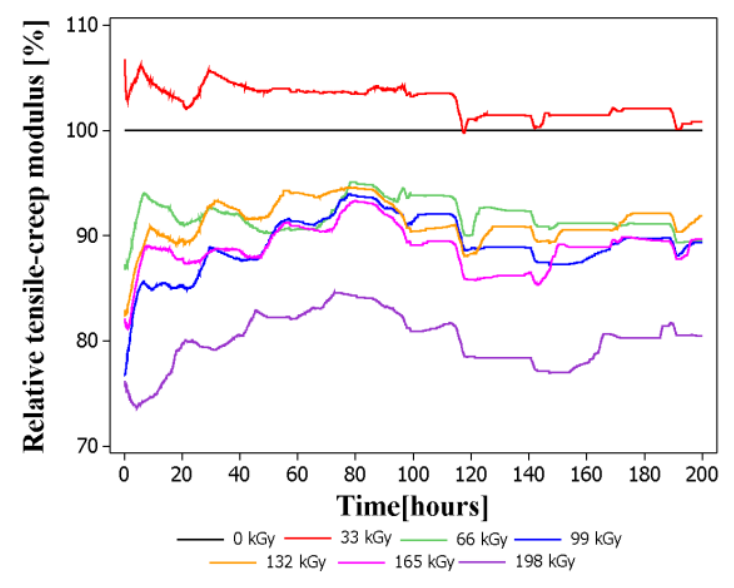

Figure 9 Tensile-creep modulus.

From the progress, the proportion of cross-linked layer is evident and the stabilization rate, which increases with the dose of irradiation.

Relative progress of the creep modulus on dedicated device does not show so rapid primary and secondary phase of test as results from the device DMA1, but it enables to imagine better progress in longer term with rapidly lower equipment costs and the progress of the test.

The choice of the device and the measurement procedure depends on the manner of use the material. Figure 6 and 9 shows the various influence of the irradiation dose on the creep properties, which is primarily caused by duration of test and posibility of stabilization of the whole process. The amount of the irradiation dose has the influence on creep modulus in time too, which is more suitable with lowest doses. These results are decisive for establishing the threshold and degradation of the spatial network.

Using a suitable measuring device can significantly shorten measurement time and also the development time of each material intended for applications where the material is subjected to creep. Based on this short measurement can already predict the next course with a certain probability. To verify the final properties is always advisable to use long-term tests.

\section{Acknowledgments}

This paper is supported by the internal grant of TBU in Zlin No. IGA/FT/2016/010 funded from the resources of specific university research and by the Ministry of Education, Youth and Sports of the Czech Republic within the National Sustainability Programme project No. LO1303 (MSMT-7778/2014) and also by the European Regional Development Fund under the project CEBIATech No. CZ.1.05/2.1.00/03.0089.

\section{References}

1. Sefidmazgi NR, Bahia HU. Mechanisms of failure in uniaxial repeated creep test and the relationship to aggregate packing. RILEM Bookseries ,11:757-71, (2016).

2. Ren, W., Zhang, D., Wang, G. and CHeng, H. Mechanical and thermal properties of bamboo pulp fiber reinforced polyethylene composites. BioResources, 11, pp. 4117-4127, (2014).

3. Ge H, Le J-, Mantell SC. Numerical modeling of stress corrosion cracking of polymers. Eng Fract Mech, 160:199-212, (2016).

4. E. Morales, J.R. White, J. Mater. Sci., 44 (17) (2009), pp. 4734-4742

5. Ge, H., Li, H., Mantell, S.C.,Annual technical conference - ANTEC, conference proceedings, 2, 1281 - 1286p., (2014).

6. Apollonio C, Covas DIC, de Marinis G, Leopardi A, Ramos HM. Creep functions for transients in HDPE pipes. Urban Water J, 11,:160-6,( 2014).

7. M. Ovsik, D. Manas, M. Manas, M. Stanek, M. Hribova, K. Kocman, D. Samek, Chem. listy, 106 (2012)

8. A. Lalande, D. Gardette Nucl. Instrum. Methods Phys. Res. B, 222 (2004)

9. D. Manas, M. Manas, M. Stanek, M. Danek, Arch. Mater. Sci. Eng., 32 (2) (2008) 